\title{
Relevance of Stress and Female Sex Hormones for Emotion and Cognition
}

\author{
J. P. ter Horst $\cdot$ E. R. de Kloet $\cdot$ H. Schächinger • \\ M. S. Oitzl
}

Received: 10 October 2011/ Accepted: 14 November 2011/Published online: 24 November 2011

(C) The Author(s) 2011. This article is published with open access at Springerlink.com

\begin{abstract}
There are clear sex differences in incidence and onset of stress-related and other psychiatric disorders in humans. Yet, rodent models for psychiatric disorders are predominantly based on male animals. The strongest argument for not using female rodents is their estrous cycle and the fluctuating sex hormones per phase which multiplies the number of animals to be tested. Here, we will discuss studies focused on sex differences in emotionality and cognitive abilities in experimental conditions with and without stress. First, female sex hormones such as estrogens and progesterone affect emotions and cognition, contributing to sex differences in behavior. Second, females respond differently to stress than males which might be related to the phase of the estrous cycle. For example, female rats and mice express less anxiety than males in a novel environment. Proestrus females are less anxious than females in the other estrous phases. Third, males perform in spatial tasks superior to females. However, while stress impairs spatial memory in males, females improve their spatial abilities, depending on the task and kind of stressor. We conclude that the differences in emotion, cognition and responses to stress between males and females over the different phases of the estrous cycle should be used in animal models for stress-related psychiatric disorders.
\end{abstract}

J. P. ter Horst $(\bowtie) \cdot$ E. R. de Kloet $\cdot$ M. S. Oitzl

Division of Medical Pharmacology, Leiden Amsterdam Center for Drug Research and Leiden University Medical Center, University of Leiden, PO Box 9502, Einsteinweg 55, 2300 RA Leiden, The Netherlands

e-mail: j.terhorst@lacdr.leidenuniv.nl

H. Schächinger

Department of Clinical Physiology, Institute of Psychobiology, University of Trier, Trier, Germany
Keywords Sex difference - Brain - Stress - Hormones · Emotion · Cognition

\section{Introduction}

It is generally accepted that chronic stress increases the vulnerability to depression, anxiety disorders, and schizophrenia. These effects of stress on the pathogenesis of psychiatric disorders show a remarkable sex difference. First of all, the prevalence rates for depression are two times higher in women than in men (Nolen-Hoeksema 2001). For post traumatic stress disorders (PTSD) the lifetime prevalence rate is $20.4 \%$ in women and $8.1 \%$ in men (Kessler et al. 1995). In eight subtypes of anxiety disorders, women are diagnosed 2.25 times more often than men with anxiety (Bekker and van Mens-Verhulst 2007). Epidemiological studies revealed that mood disorders are at least twice as common in women as in men (Kessler 2003; Lewinsohn et al. 1998; Steiner et al. 2003; Wittchen and Jacobi 2005). Alternatively, the incidence of schizophrenia is 1.4 times higher in men than women (McGrath 2006). While more men than women develop schizophrenia at the age of $16-25$, the incidence of schizophrenia is higher in women between 25 and 30 years of age (Maguire 2002). Participants of epidemiological and clinical studies are also predominantly men, although it is known that women respond differently to drug treatment (Soldin and Mattison 2009). Already in 1993 the National Institute of Health (NIH) decided that clinical trials should include women as well as men (Beery and Zucker 2011).

Remarkably, no initiative as proposed by the NIH for human studies is seen in animal research. Studies using male animals outnumber those using females. In neuroscience this 
ratio is 5.5:1 (Beery and Zucker 2011). This is surprising since preclinical research can provide a wealth of data not only on sex differences in models reflecting the onset of stress-related psychiatric disorders, but also on the regulation of the stress reaction in male and female animals (Palanza 2001; Schmidt et al. 2010). Yet, researchers studying in animals the mechanism underlying anxiety and depression still prefer male subjects. This priority of the male in studies seems not just neglecting the other sex, it also is denying the biological differences between females and males.

There are serious arguments for using female animals (predominantly rats and mice) when designing models for stress-related psychiatric disorders and pharmacotherapy. However, the main argument for not using female animals is their estrous cycle, which is characterized by a distinct secretion pattern of estrogens and progesterone (Butcher et al. 1974). In rats and mice, one estrous cycle lasts four to 5 days and consists of four phases: the proestrus, estrus, metestrus, and the diestrus. During proestrus concentrations of both estrogen and progesterone are elevated. In the estrus phase both sex hormones decrease and in the metestrus and diestrus a slight elevation of progesterone occurs, which returns to baseline at the end of the diestrus phase. Therefore, taking into account the hormonal state of the female rodent, many more females than males have to be examined, multiplying the number of subjects per experiment. Moreover, variations in sex hormone levels might complicate the results (Beery and Zucker 2011; Wotjak 2004). Clearly, there is a paradox: The arguments against the use of female animals in research are of a practical kind, while at the same time the biological significance of sex hormones for mental health and disease is acknowledged.

In this review, we will first discuss the difference in the hypothalamus-pituitary-adrenal (HPA) axis in both female and male animals. Next, an overview of sex differences in cognition and emotion is given to highlight the differences in male and female behavior. Then, the effect of stress and sex hormones on cognition and emotion is reviewed, but only those studies are included where at least two or three of the estrous cycle phases were described in "intact" (i.e., with intact ovaries) females. Finally, sex differences in the role of corticosteroid stress hormone receptors on cognition and emotion are reported.

\section{The HPA Axis in Females and Males}

Coping with stress is promoted by the action of the HPA axis and the sympathetic adrenomedullary system that operate in complementary fashion in the context of behavioral stress response patterns shaped by gene-environment interactions (de Kloet et al. 1998). Here we will focus on the HPA axis, in particular on the corticosteroid hormones and their regulation.

\section{The HPA Axis}

Corticotropin-releasing hormone $(\mathrm{CRH})$ and vasopressin (AVP) from the paraventricular nucleus (PVN) of the hypothalamus activate the synthesis of pro-opiomelanocortin (POMC) in the anterior pituitary, resulting in the secretion of adreno-corticotropin (ACTH) into the blood circulation (Fig. 1). ACTH stimulates the adrenal cortex to secrete glucocorticoids: mainly cortisol in humans and corticosterone in rats and mice.

In the brain, corticosterone binds to two receptor types, the mineralocorticoid receptor (MR) expressed mainly in the limbic areas and the glucocorticoid receptor (GR) distributed widely in the brain (de Kloet et al. 1998, 2005; McEwen et al. 1986). The affinity of corticosterone to MR is higher than to GR (Reul and de Kloet 1985). Therefore, MR become occupied and activated at much lower concentrations of circulating corticosterone than GR, which require peak concentrations reached after stress or during the circadian peak. The MR mediated actions become manifest in particular during the initial response of the HPA axis to stressful situations while GR contribute to the negative feedback of the HPA axis by terminating the stress response, while facilitating recovery and behavioral adaptation (de Kloet et al. 1998). Balanced activation of MR and GR is considered essential for efficient regulation of the stress response which is crucial for the maintenance of homeostasis and mental health (Oitzl et al. 2010).

The reactivity of the HPA axis differs in male and female subjects (Fig. 1). Female rats secrete higher amounts of corticosterone than males in resting conditions (Carey et al. 1995; Critchlow et al. 1963; Figueiredo et al. 2002) and their circadian rhythm contains more and higher pulses of corticosterone (Seale et al. 2004). In response to stress, AVP plasma levels and ACTH levels are increased (Williams et al. 1985; Le Mevel et al. 1979) and corticosterone levels rise higher and remain elevated for longer periods in females than in males (Figueiredo et al. 2002; Kitay 1961; Le Mevel et al. 1979; Pollard et al. 1975). Corticosteroid binding globulin (CBG) is also found in higher amounts in female than male rats. CBG is positively regulated by estrogen (Young and Altemus 2004). This would imply that free (biologically active) corticosteroid concentrations are similar or even lower in females than in males (Gala and Westphal 1965). In addition, moderate and strong stressors such as swimming and restraint initiate a fast increase (within $5 \mathrm{~min}$ ) of circulating CBG, keeping free corticosterone concentrations attenuated for about $20 \mathrm{~min}$. This highly dynamic role has been discovered most recently (Qian et al. 2011). Following stress, CBG 


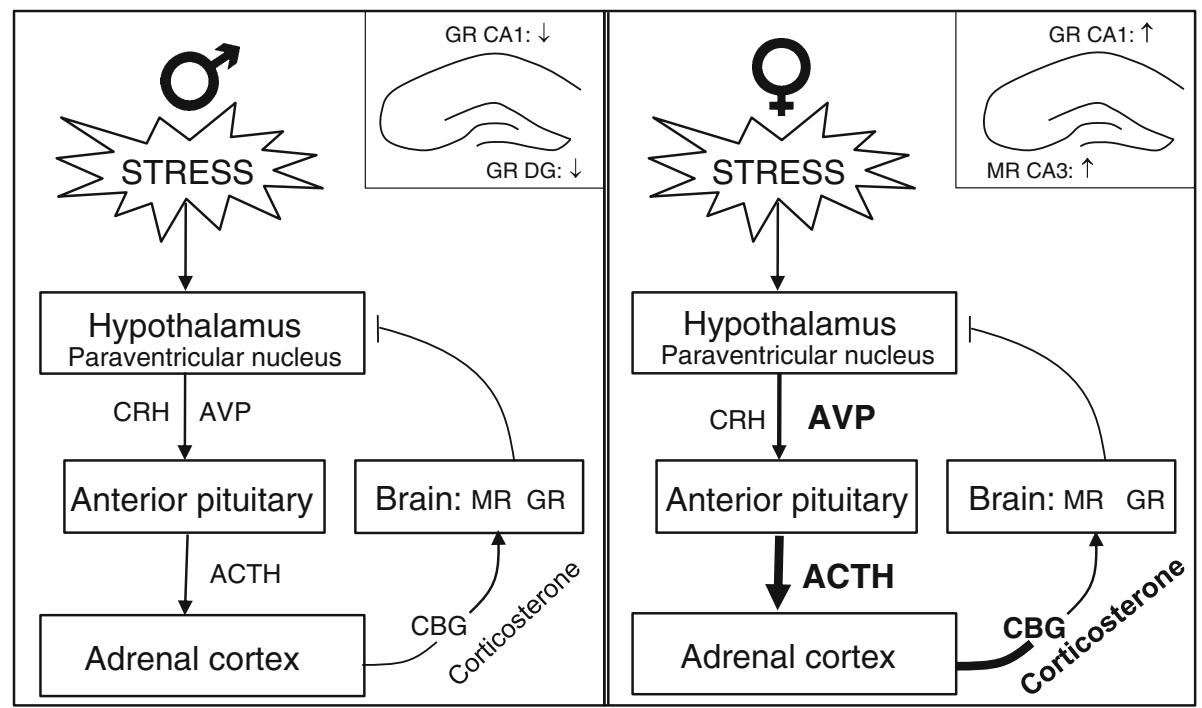

Fig. 1 Schematic presentation of the HPA axis in male (left panel) and female (right panel) rats under stress conditions. An insert of the hippocampus is shown in each part illustrating the sex difference in stress hormone receptors, based on Karandrea et al. (2000) and Kitraki et al. (2004). The increase in corticosterone in females is higher than in males and the highest during the proestrus phase. It is

was found significantly reduced (Tannenbaum et al. 1997) resulting in an increase in free corticosterone in both males and females. Thus, CBG is actively regulated by stress and sex hormones.

\section{Sex Differences in Corticosteroid Receptors}

The binding capacity of receptors for corticosterone in cytosol of the hippocampus is higher in female rats, while the affinity of the receptors is higher in males (Turner and Weaver 1985). Next, corticosterone binding was distinguished in mineralocorticoid and glucocorticoid receptors. The MR of male rats has a threefold higher binding affinity than the MR in females, with no difference for the GR (Turner 1992) suggesting that under low corticosterone levels the MR in females is relatively less occupied and activated (Turner 1997). In addition, female mice were reported to express less MR than males (Lin et al. 2011). Under chronic stress the sex-specific patterns of MR and GR change. A down-regulation of GR binding (immunoreactivity) in the dentate gyrus and CA1 region in the hippocampus of male rats (Karandrea et al. 2000; Kitraki et al. 2004) was opposed by an increase in GR binding in the CA1 region of female rats (see inset Fig. 1). Concurrently, MR binding was increased in the CA3 region of female but not male rats.

These findings provide evidence for the existence of both regional and gender specificity in the regulation of the stress response in brain areas which are crucial for emotion and cognition. not known how and whether the other parts of the HPA system differ during the estrous cycle. Thicker arrows depict an increase in hormone levels. $A V P$ vasopressin; $A C T H$ adreno-corticotropin; $C B G$ corticosteroid binding globulin; $C R H$ corticotroping-releasing hormone; $M R$ mineralocorticoid receptor; $G R$ glucocorticoid receptor; $C A$ cornu ammonis region of the hippocampus; $D G$ dentate gyrus

\section{The Estrous Cycle and the HPA Axis}

So far, we have presented female/male differences in the activity and regulation of the HPA axis, but what happens to the regulation of this stress system in the course of the estrous cycle? In the proestrus phase, resting and stressinduced corticosterone concentrations are higher than in estrus and diestrus phases (Atkinson and Waddell 1997; Carey et al. 1995; Critchlow et al. 1963; Figueiredo et al. 2002; Pollard et al. 1975; Viau and Meaney 1991). In addition, Carey et al. (1995) elegantly demonstrated an interaction of sex and stress hormones: Estradiol decreases hippocampal MR mRNA expression and binding, whereas progesterone reverses this effect. Progesterone also binds with appreciable affinity to the MR. Chronic social stress disrupts the estrous cycle in rats, resulting in a phenotype with depression-like features (Herzog et al. 2009). Already 5 days of stress is enough to desynchronize the estrous cycle of rats (Pollard et al. 1975). Furthermore, spironolactone (a MR antagonist with affinity to progesterone and androgen receptors) disrupts the estrous cycle in rats (Nagi and Virgo 1982) and causes menstrual irregularities in humans (de Gasparo et al. 1987). Moreover, it is generally known that chronic stress affects the menstrual cycle.

Taken together, sex- and stress hormone interactions are indeed complex and so far there is little understanding of the underlying regulatory mechanism. The main reason is the difficulty to set up experimental designs in the 'classical way' as already acute stress affects the regularity of the estrous cycle. Refined molecular approaches using 
selective targeting of genes regulated by sex and corticosteroid hormones are the tools for future studies.

\section{Distinct Emotional Behavior in Male and Female Rats and Mice}

Coping with stress involves emotionality (Fig. 2). Emotionality of rats and mice is most often inferred from their behavior in novel environments. Usually, suppression of activity and avoidance of certain parts of the environment are interpreted as anxiety-like/related behavior. Interestingly, female rats and mice show less anxiety-like behavior and arousal in novel environments than males. Overall, males tend to walk less, freeze, and defecate more than females (Adamec et al. 2006; Tropp and Markus 2001). Avoidance of open areas is another index for anxiety. Open arms of an elevated plus maze (EPM) are entered more readily by females than males (Bowman et al. 2001; Johnston and File 1991; Leret et al. 1994; Rodgers and Cole 1993; Zimmerberg and Farley 1993). Likewise the arena of the open field is explored more extensively by females (Kennett et al. 1986). In addition, female mice spend more time in the light compartment of a light-dark box than males (Adamec et al. 2006; Voikar et al. 2001). Others have reported less open arm exploration in the EPM in female than male mice related to age (Frick et al. 2000) or no difference (Marcondes et al. 2001; Rodgers and Cole 1993; Voikar et al. 2001).

The type of the stressor is of relevance for the sexspecific behavioral effects. Open arm exploration in the EPM decreased in male rats following restraint stress (Bowman et al. 2009), isolation stress (Weiss et al. 2004); and in male mice following confrontation with a predator (Adamec et al. 2006), and a psycho-emotional stressor enforced by cohabitation with an aggressive male (Avgustinovich and Kovalenko 2010). Isolation stress in male mice reduced anxiety as was seen by more locomotion in the open field, more open arm exploration in the EPM and more time spent in the light part of the light/dark box

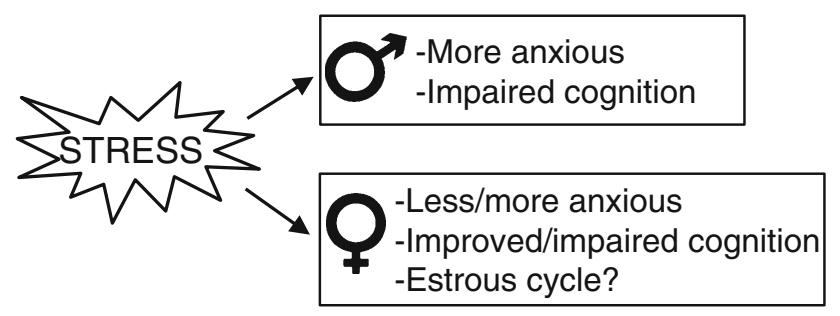

Fig. 2 Stress shows clear effects on emotion and cognition in males but not in females. Stress induces more anxiety in male rodents and impairs cognitive abilities. However, in female rodents stress can decrease but also increase anxiety and impair or enhance their cognitive abilities depending on the type of learning task and stressor
(Guo et al. 2004). In females, open arm exploration was reduced following odor of but also after confrontation with a predator (Adamec et al. 2006) and following the experience of a psycho-emotional stressor (Avgustinovich and Kovalenko 2010). Restraint stress did not affect open arm exploration in female rats on the EPM (Bowman et al. 2009). Results of exposure to an isolation stressor are not consistent for females, apparently depending on the task: reduced locomotor activity (Palanza 2001; Palanza et al. 2001) or no effect (Guo et al. 2004), but also less anxiety expressed by an increase in time spent in the light compartment of the light/dark box (Guo et al. 2004).

In addition to sex differences, the variation in the concentration of circulating sex hormones over the cycle is correlated with anxiety-related behavior. Proestrus and estrus rats showed less anxiety in the EPM by spending more time in the open arms of the EPM than diestrus rats (Frye et al. 2000; Mora et al. 1996; Diaz-Veliz et al. 1997; Gouveia et al. 2004; Marcondes et al. 2001; Walf et al. 2009). In particular, females in proestrus displayed shorter latencies to enter an open field (Palanza 2001; Palanza et al. 2001); longer duration in a mirror chamber (Walf et al. 2009); less freezing in response to a shock in the defensive burying task (Frye et al. 2000) and a better memory expressed by longer latencies to cross to the shock-compartment in an inhibitory avoidance task (Walf and Frye 2007). Furthermore, proestrus females had longer social interactions with conspecifics (Frye et al. 2000; Palanza 2001; Palanza et al. 2001). These findings suggest that estrogen and progesterone modulate anxiety-like behavior.

Overall, stress tends to make males less anxious while in female animals changes in anxiety depends on the type of stressor (Fig. 2). During proestrus and estrus rats and mice display less anxiety-like behavior than during diestrus. These differential effects of sex- and stress hormones on emotionality already predict that the level of anxiety will contribute to cognitive processes of memory formation.

\section{Sex- and Stress-Hormones, Synaptic Plasticity, and Memory}

Learning and memory has been extensively studied using plasticity of the neural network of the hippocampus as a model system, together with alterations in dendrite complexity and spine density. Remarkably, the estrous cycle of female rats is paralleled by rapid fluctuations in spine density in the CA1 region of the hippocampus. During proestrus, spine density and number of synapses is the highest, followed by a rapid decrease in the estrus phase and intermediate spine density in the diestrus (McEwen 2010; Woolley et al. 1990a; Woolley and McEwen 1992). 
Tracy Shors and colleagues repeatedly demonstrated the relevance of the estrus phase for learning and memory. When compared to males, especially proestrus female rats are superior in learning the eye-blink conditioning task and not females in the other estrous phases (Bangasser and Shors 2007; Dalla et al. 2009; Waddell et al. 2008; Wood et al. 2001; Wood and Shors 1998).

In addition to sex hormones, corticosteroids are known to modulate neuronal plasticity and cognition. Morphological features comprised of increased and decreased complexity of dendrites, number and type of synapses depending on the brain area investigated have been reported. Chronic stress and corticosterone both resulted in decreased dendritic morphology in the dorsomedial striatum and CA3 region of the hippocampus (Dias-Ferreira et al. 2009; McLaughlin et al. 2007; Woolley et al. 1990b), however, increased length and branching of the dendrites were found in the dorsolateral striatum (Dias-Ferreira et al. 2009). Chronic stress and corticosterone also impaired spatial learning and decision making (Bodnoff et al. 1995; Conrad et al. 1996, 2003; Dachir et al. 1993; Dias-Ferreira et al. 2009; Luine et al. 1994; McLaughlin et al. 2007). These data are derived from studies in male rats. Moreover, Luine et al. (2007) reported sex-dependent behavioral and neural changes in rats depending on the duration of chronic stress and age.

Early life stress such as maternal separation and deprivation is one of the major risk factors for stress-related pathologies. Brain morphology and learning were differentially affected in young adult male and female rats that had been separated from their mother for $24 \mathrm{~h}$ on postnatal day 3 (Oomen et al. 2010, 2011). In males, neurogenesis was reduced, along with a loss of dendritic mass and impaired spatial learning while memory for an aversive event was strengthened and corticosterone facilitated LTP. Maternally deprived females, in contrast, had reduced number of cells in the dentate gyrus with alterations in the dendritic arrangement, but neurogenesis, LTP, spatial learning, and contextual fear conditioning were not affected. The consequences of the same adverse early life stress are clearly sex-dependent and might align the vulnerability or resilience to stress-related disorders in later life.

\section{Spatial Learning and Memory}

Interestingly, the majority of studies in rats and mice did not find a clear gender difference in spatial learning. The studies which did find a gender difference observed that male rats and mice performed better than females in the Morris water maze (Beiko et al. 2004; Berger-Sweeney et al. 1995; Frick et al. 2000; Frye 1995; Markowska 1999; Perrot-Sinal et al. 1996; Roof 1993), the Y-maze (Conrad et al. 2004), the radial arm maze (Roof 1993) and the
Barnes maze (Barrett et al. 2009; O'Leary et al. 2011). However, one study showed that female mice performed superior to males in the Morris water maze (Lamberty and Gower 1988). In addition, altering the experimental conditions and introducing a pretraining period to the water maze resulted in comparable spatial navigation of both sexes (Beiko et al. 2004; Bucci et al. 1995; Perrot-Sinal et al. 1996; Warren and Juraska 1997).

The water maze task itself is a severe stressor for mice and rats due to the high degree of novelty and the lifethreatening condition. An extra external stressor, depending on the level and timing of the stressful situation, will affect emotionality, performance, spatial learning, and memory. As described above, stress system activity differs between the sexes. Moreover, stress seems to affect spatial learning differently in males and females. In response to acute and chronic stress, spatial learning and memory is impaired in male rats in several spatial tasks such as the radial arm maze, Y-maze, and Morris water maze (Bowman et al. 2001; Conrad et al. 2003, 2004; Diamond et al. 1999; Kitraki et al. 2004; Luine et al. 1994). In female rats and mice, modulation of spatial learning and memory is depending on the experimental paradigm and the type of stressor. Chronically restraint stressed female rats showed enhanced spatial performance in the radial arm maze and Morris water maze (Bowman et al. 2001; Kitraki et al. 2004) and acute stress improved spatial memory in the Y-maze (Conrad et al. 2004). However, exposing female rats to isolation stress impaired spatial learning in the radial arm maze and in the Morris water maze (Daniel et al. 1999) and chronic restraint stress impaired females in the Y-maze (Conrad et al. 2003). Apparently, females are more sensitive to the effect of stress, depending on the duration and the type of stressor and the spatial task.

Is this increased sensitivity to stress of female rodents related to the estrous cycle? The few studies that address the estrous phases separately report an impairment in spatial performance during estrus in the Morris water maze (Frick and Berger-Sweeney 2001; Frye 1995), and the proestrus in the water maze and radial arm maze (Pompili et al. 2010; Bowman et al. 2001, respectively). Furthermore, pretraining might alleviate the level of task-related stress and could contribute to the improved spatial learning in the estrus phase (Warren and Juraska 1997). Depending on the phase of the estrous cycle facilitation as well as impairment of spatial performance and memory have been reported.

\section{Are Learning Strategies Sex-Dependent?}

Males and females might use different strategies solving a task. Depending on the design of a behavioral task more than one learning strategy can be used, e.g., a spatial or a 
stimulus-response strategy. The spatial strategy requires the relation of multiple stimulus configurations in the surrounding environment and an intact hippocampus (White and McDonald 2002). The stimulus-response strategy makes use of a single stimulus and requires the activation of the caudate nucleus (Packard and Knowlton 2002; Schwabe et al. 2010).

The preferred strategy of male mice and rats is spatial (Bettis and Jacobs 2009; Schwabe et al. 2008, 2010; Tropp and Markus 2001). Chronic and acute stress allows a switch from spatial towards a stimulus-response strategy (Schwabe et al. 2008, 2010) in male mice. Females apply both spatial and stimulus-response strategies (Bettis and Jacobs 2009; Korol et al. 2004; Pleil and Williams 2010; Tropp and Markus 2001). However, the spatial strategy was predominantly applied during proestrus (Korol et al. 2004; Pleil and Williams 2010). Whether stress alters the problem solving strategy in female mice or rats has not been reported yet.

\section{Short-Term Memory Tasks Sensitive to Sex-} and Stress-Hormones

In the object placement task, one of two familiar objects is moved to a different location. After a short delay, the animal returns. If it detects this "relocation", it will explore this object more than the one that remained in the same position. Results comparing male and female performances in the object placement task are diverse. Both male rats and mice showed overall more object exploration than females (Beck and Luine 2002; Frick and Gresack 2003; Sutcliffe et al. 2007); but others found no sex differences (Bowman et al. 2009; Tropp and Markus 2001). Chronic restraint stress prior to the task increased exploration of the relocated object in female rats, but did not affect males (Beck and Luine 2002; Bowman et al. 2009). Exploration of a relocated object was increased especially in estrus and proestrus females compared to diestrus females (Frye et al. 2007; Paris and Frye 2008; Sutcliffe et al. 2007; Tropp and Markus 2001) supporting the impact of the estrous phase for behavior.

The object recognition task requires the functionality of prefrontal cortex regions. A novel object replaces one of at least two familiar objects. If recognized, exploration of the novel object should be increased. Female rats and mice explore the novel object more than males (Beck and Luine 2002; Bettis and Jacobs 2009; Bowman et al. 2009; Sutcliffe et al. 2007). Chronic restraint and chronic mild stress did not affect exploration of the novel object in females but decreased novel object exploration in males (Beck and Luine 2002; Bowman et al. 2009; Elizalde et al. 2008; Li et al. 2008). Furthermore, a clear effect of the estrus phase was seen with more exploration of the novel object during proestrus than during the other phases (Paris and Frye 2008; Walf et al. 2006, 2009).

\section{Associative Learning}

Eyeblink conditioning is a classical conditioning task. In this paradigm, the animal is presented with a noise (conditioned stimulus), which is followed by an aversive stimulation to the eye (e.g., an air puff), which causes the animal to blink. The blinking becomes conditioned as the animal learns that the noise predicts the air puff (Dalla and Shors 2009). Rats in proestrus acquire the task faster than males do (Bangasser and Shors 2007; Dalla et al. 2009; Hodes and Shors 2005; Wood and Shors 1998). Stress facilitates eyeblink conditioning in male rats, but impairs it in female rats especially in the diestrus phase (Bangasser and Shors 2008; Hodes and Shors 2007; Leuner and Shors 2006; Wood et al. 2001; Wood and Shors 1998).

\section{Corticosteroid Receptors in Emotion and Cognition}

The effects of corticosteroids are exerted via their receptors, MR and GR to modulate emotions and cognitive abilities (de Kloet et al. 2005). MR is thought to be implicated in emotions related to anxiety, memory acquisition (appraisal of information and response selection), whereas activation of GR modulates the consolidation of information (Lupien and McEwen 1997; Oitzl and de Kloet 1992). The balanced activation of MR and GR is critical for neuronal excitability, stress responsiveness, and behavioral adaptation (De Kloet et al. 1998). Recently fast, non-genomic effects of glucocorticoids have been reported (Di et al. 2003; Groeneweg et al. 2011; Karst et al. 2005, 2010), extending the spectrum and the impact of glucocorticoids in the various time domains during learning and memory and stress (Oitzl et al. 2010).

Pharmacological and genetic studies demonstrated a clear role for GR in memory consolidation. Mice with genetically modified GR have been suggested as models for depression (Gass et al. 2001), but only male mice have been tested. To further unravel the role of MR, genetic mouse models, such as mice with either MR deficiency in the forebrain (MR ${ }^{\mathrm{CaMKCre}}$; Berger et al. 2006) or general MR overexpression (Rozeboom et al. 2007) were designed. MR overexpressing mice of both sexes showed less anxiety-related behavior in the EPM and the open field (Rozeboom et al. 2007). However, behavioral parameters indicative for anxiety, such as locomotion in the open field, open arm exploration in the elevated zero maze and the duration in the light compartment of the light/dark box, were not affected in $\mathrm{MR}^{\mathrm{CaMKCre}}$ males and females (Berger et al. 2006). In the novel object recognition, both male and female $\mathrm{MR}^{\mathrm{CaMKCre}}$ mice explored a novel object more than control mice did. Spatial learning of both sexes of the $\mathrm{MR}^{\mathrm{CaMKCre}}$ mice was delayed as they needed more training 
than control animals to learn the water maze task. A sexdependent effect was seen in spatial working memory in the radial arm maze with female $\mathrm{MR}^{\mathrm{CaMKCr}}$ mice making more re-entry errors and less correct responses during the first 8 choices (Berger et al. 2006). It seems that behavioral flexibility is impaired in the absence of forebrain MR.

There is little data regarding behavioral response characteristics under stress. So far, we found that acute restraint stress resulted in higher arousal and less exploration in female $\mathrm{MR}^{\mathrm{CaMKCre}}$ mice, indicative for increased anxiety (Brinks et al. 2009). Stronger anxiety-like behavior was also expressed as more freezing to cue in female $\mathrm{MR}^{\mathrm{CaMKCre}}$ mice compared to controls during the acquisition in a fear conditioning task. Consecutively, fear memory was increased as was seen by higher amounts of freezing to both cue and context compared to control mice (Brinks et al. 2009). How male $\mathrm{MR}^{\mathrm{CaMKCre}}$ mice respond to stress is not known yet.

In summary, these results support the involvement of MR in the appraisal of novel situations. Moreover, we get more and more evidence for sex-specific emotional and cognitive behavioral patterns that are under the influence of corticosteroid receptors. Currently, we are following this lead in the design of our studies by testing both sexes and taking into account the estrous cycle.

\section{Summary and Conclusion}

We have presented and highlighted data demonstrating sex differences in the regulation of the HPA axis, effects on neural plasticity and behavioral responses in rats and mice which serve as model systems for emotion and cognition.
These data show that sex-dependent differences in emotionality and cognition exist, and that the reactivity of the HPA axis is different between males and females. Noticeably, stress can have opposite effects on emotionality and cognition in male and female subjects (Fig. 2). In the majority of studies, stress increases emotionality and impairs cognition in males, whereas in female animals stress alleviates emotionality and enhances cognition, depending on learning task and stressor. As a consequence, stress can promote behavioral adaptation in the female, and not in the male. Different effects of stress on the behavior of both sexes combined with the sex differences in the stress system underline the importance to include both male to female subjects, specifically in the search for animal models for stress-related psychiatric disorders.

The data discussed in the previous sections are summarized in Fig. 3. This figure demonstrates that the estrous cycle is a strong determinant in the level of emotionality and the cognitive capacity of female rodents. Compared to other phases of the estrous cycle, females in proestrus are exposed to high levels of sex- and stress hormones, which are paralleled by morphological changes in the brain such as increase in spine density. At that time the females express less emotionality and enhanced learning of simple associative tasks as eye-blink conditioning, but are impaired in performing more complex learning tasks. Interestingly, acute stress has the same effect on all of the above parameters. However, whether and how stress affects females'ability in each stage of the estrous cycle in learning tasks is not known and requires more research.

Studying the interaction between sex and stress hormones will open new avenues for research in animal

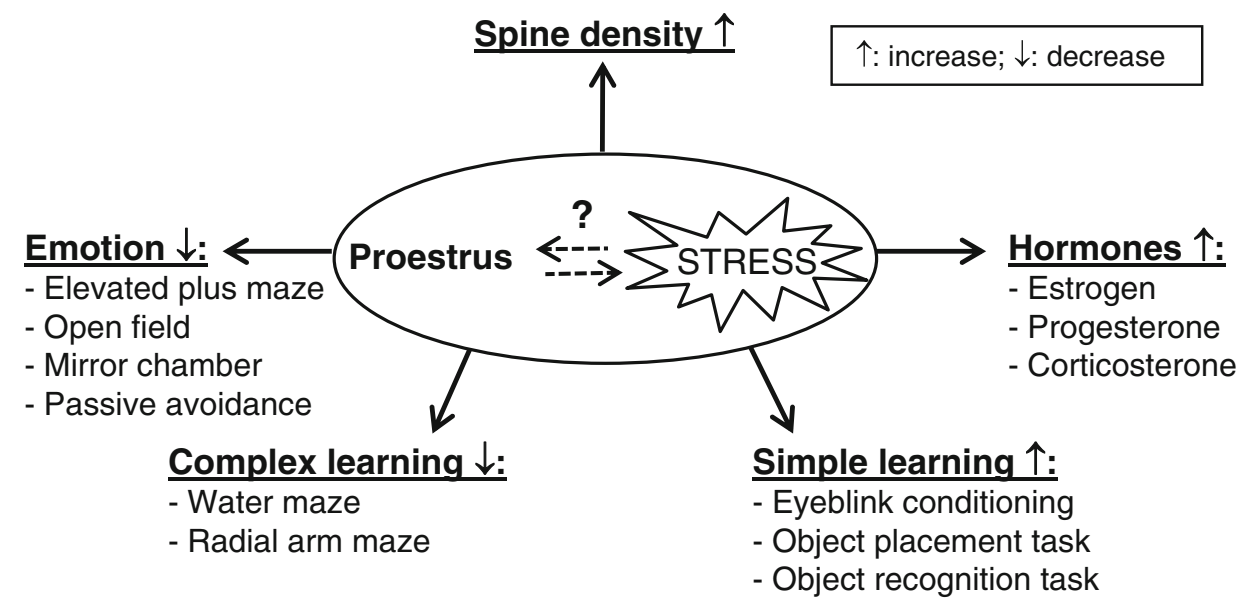

Fig. 3 The effect of the estrous cycle on emotion and cognition. Proestrus females are exposed to high sex and stress hormone levels. In parallel, morphology of neurons show an increase in spine density. In proestrus, females are also less emotional compared to the other estrus phases and show improved learning in simple cognitive tasks. In complex learning tasks proestrus females are impaired. The effect of acute stress on all of these parameters in females is known; however, it is unknown what the effect of acute stress on the estrous cycle and therefore on these parameters is. Revealing the effects of acute stress in combination with the estrous cycle requires more research 
models and may contribute to the understanding of sex differences in resilience and vulnerability to psychiatric disorders as well as the efficacy of pharmacological treatment.

Acknowledgments This work was supported by the European Science Foundation to JPtH and ERdeK (Eurocores, 07-EuroSTRESS-FP-005), NWO-DFG-IRTG-DN 95-420 to MSO and HS and the Royal Netherlands Academy of Sciences KNAW to ERdKDr.J.Dobberke 2010-2009 to JPtH.

Open Access This article is distributed under the terms of the Creative Commons Attribution Noncommercial License which permits any noncommercial use, distribution, and reproduction in any medium, provided the original author(s) and source are credited.

\section{References}

Adamec R, Head D, Blundell J, Burton P, Berton O (2006) Lasting anxiogenic effects of feline predator stress in mice: sex differences in vulnerability to stress and predicting severity of anxiogenic response from the stress experience. Physiol Behav 88(1-2):12-29. doi:10.1016/j.physbeh.2006.03.005

Atkinson HC, Waddell BJ (1997) Circadian variation in basal plasma corticosterone and adrenocorticotropin in the rat: sexual dimorphism and changes across the estrous cycle. Endocrinology 138(9):3842-3848

Avgustinovich DF, Kovalenko IL (2010) Gender-related characteristics of responding to prolonged psychoemotional stress in mice. Neurosci Behav Physiol 40(3):257-262. doi:10.1007/s11055010-9252-1

Bangasser DA, Shors TJ (2007) The hippocampus is necessary for enhancements and impairments of learning following stress. Nat Neurosci 10(11):1401-1403. doi:10.1038/nn1973

Bangasser DA, Shors TJ (2008) The bed nucleus of the stria terminalis modulates learning after stress in masculinized but not cycling females. J Neurosci 28(25):6383-6387. doi:10.1523/JNEUROSCI. 0831-08.2008

Barrett GL, Bennie A, Trieu J, Ping S, Tsafoulis C (2009) The chronology of age-related spatial learning impairment in two rat strains, as tested by the Barnes maze. Behav Neurosci 123(3):533-538. doi:10.1037/a0015063

Beck KD, Luine VN (2002) Sex differences in behavioral and neurochemical profiles after chronic stress: role of housing conditions. Physiol Behav 75(5):661-673

Beery AK, Zucker I (2011) Sex bias in neuroscience and biomedical research. Neurosci Biobehav Rev 35(3):565-572. doi: 10.1016/j.neubiorev.2010.07.002

Beiko J, Lander R, Hampson E, Boon F, Cain DP (2004) Contribution of sex differences in the acute stress response to sex differences in water maze performance in the rat. Behav Brain Res 151(12):239-253. doi:10.1016/j.bbr.2003.08.019

Bekker MH, van Mens-Verhulst J (2007) Anxiety disorders: sex differences in prevalence, degree, and background, but genderneutral treatment. Gend Med 4(Suppl B):S178-S193

Berger S, Wolfer DP, Selbach O, Alter H, Erdmann G, Reichardt HM, Chepkova AN, Welzl H, Haas HL, Lipp HP, Schutz G (2006) Loss of the limbic mineralocorticoid receptor impairs behavioral plasticity. Proc Natl Acad Sci USA 103(1):195-200. doi: 10.1073/pnas.0503878102

Berger-Sweeney J, Arnold A, Gabeau D, Mills J (1995) Sex differences in learning and memory in mice: effects of sequence of testing and cholinergic blockade. Behav Neurosci 109(5):859-873
Bettis TJ, Jacobs LF (2009) Sex-specific strategies in spatial orientation in C57BL/6 J mice. Behav Process 82(3):249-255. doi:10.1016/j.beproc.2009.07.004

Bodnoff SR, Humphreys AG, Lehman JC, Diamond DM, Rose GM, Meaney MJ (1995) Enduring effects of chronic corticosterone treatment on spatial learning, synaptic plasticity, and hippocampal neuropathology in young and mid-aged rats. J Neurosci 15(1 Pt 1):61-69

Bowman RE, Zrull MC, Luine VN (2001) Chronic restraint stress enhances radial arm maze performance in female rats. Brain Res 904(2):279-289

Bowman RE, Micik R, Gautreaux C, Fernandez L, Luine VN (2009) Sex-dependent changes in anxiety, memory, and monoamines following 1 week of stress. Physiol Behav 97(1):21-29. doi: 10.1016/j.physbeh.2009.01.012

Brinks V, Berger S, Gass P, de Kloet ER, Oitzl MS (2009) Mineralocorticoid receptors in control of emotional arousal and fear memory. Horm Behav 56(2):232-238. doi:10.1016/j.yhbeh. 2009.05.003

Bucci DJ, Chiba AA, Gallagher M (1995) Spatial learning in male and female long-evans rats. Behav Neurosci 109(1):180-183

Butcher RL, Collins WE, Fugo NW (1974) Plasma concentration of LH, $\mathrm{FSH}$, prolactin, progesterone and estradiol-17beta throughout the 4-day estrous cycle of the rat. Endocrinology 94(6):1704-1708

Carey MP, Deterd CH, de Koning J, Helmerhorst F, de Kloet ER (1995) The influence of ovarian steroids on hypothalamicpituitary-adrenal regulation in the female rat. J Endocrinol 144(2):311-321

Conrad CD, Galea LA, Kuroda Y, McEwen BS (1996) Chronic stress impairs rat spatial memory on the $\mathrm{Y}$ maze, and this effect is blocked by tianeptine pretreatment. Behav Neurosci 110(6):1321-1334

Conrad CD, Grote KA, Hobbs RJ, Ferayorni A (2003) Sex differences in spatial and non-spatial Y-maze performance after chronic stress. Neurobiol Learn Mem 79(1):32-40

Conrad CD, Jackson JL, Wieczorek L, Baran SE, Harman JS, Wright RL, Korol DL (2004) Acute stress impairs spatial memory in male but not female rats: influence of estrous cycle. Pharmacol Biochem Behav 78(3):569-579. doi:10.1016/j.pbb.2004.04.025

Critchlow V, Liebelt RA, Bar-Sela M, Mountcastle W, Lipscomb HS (1963) Sex difference in resting pituitary-adrenal function in the rat. Am J Physiol 205(5):807-815

Dachir S, Kadar T, Robinzon B, Levy A (1993) Cognitive deficits induced in young rats by long-term corticosterone administration. Behav Neural Biol 60(2):103-109

Dalla C, Shors TJ (2009) Sex differences in learning processes of classical and operant conditioning. Physiol Behav 97(2):229 238. doi:10.1016/j.physbeh.2009.02.035

Dalla C, Papachristos EB, Whetstone AS, Shors TJ (2009) Female rats learn trace memories better than male rats and consequently retain a greater proportion of new neurons in their hippocampi. Proc Natl Acad Sci USA 106(8):2927-2932. doi:10.1073/pnas. 0809650106

Daniel JM, Roberts SL, Dohanich GP (1999) Effects of ovarian hormones and environment on radial maze and water maze performance of female rats. Physiol Behav 66(1):11-20

de Gasparo M, Joss U, Ramjoue HP, Whitebread SE, Haenni H, Schenkel L, Kraehenbuehl C, Biollaz M, Grob J, Schmidlin J et al (1987) Three new epoxy-spirolactone derivatives: characterization in vivo and in vitro. J Pharmacol Exp Ther 240(2): 650-656

De Kloet ER, Vreugdenhil E, Oitzl MS, Joels M (1998) Brain corticosteroid receptor balance in health and disease. Endocr Rev 19(3):269-301

de Kloet ER, Joels M, Holsboer F (2005) Stress and the brain: from adaptation to disease. Nat Rev Neurosci 6(6):463-475. doi:10.1038/ nrn1683 
Di S, Malcher-Lopes R, Halmos KC, Tasker JG (2003) Nongenomic glucocorticoid inhibition via endocannabinoid release in the hypothalamus: a fast feedback mechanism. J Neurosci 23(12): 4850-4857

Diamond DM, Park CR, Heman KL, Rose GM (1999) Exposing rats to a predator impairs spatial working memory in the radial arm water maze. Hippocampus 9(5):542-552. doi:10.1002/(SICI)10981063(1999)9:5<542:AID-HIPO8>3.0.CO;2-N

Dias-Ferreira E, Sousa JC, Melo I, Morgado P, Mesquita AR, Cerqueira JJ, Costa RM, Sousa N (2009) Chronic stress causes frontostriatal reorganization and affects decision-making. Science 325(5940): 621-625. doi:10.1126/science. 1171203

Diaz-Veliz G, Alarcon T, Espinoza C, Dussaubat N, Mora S (1997) Ketanserin and anxiety levels: influence of gender, estrous cycle, ovariectomy and ovarian hormones in female rats. Pharmacol Biochem Behav 58(3):637-642

Elizalde N, Gil-Bea FJ, Ramirez MJ, Aisa B, Lasheras B, Del Rio J, Tordera RM (2008) Long-lasting behavioral effects and recognition memory deficit induced by chronic mild stress in mice: effect of antidepressant treatment. Psychopharmacology (Berl) 199(1):1-14. doi:10.1007/s00213-007-1035-1

Figueiredo HF, Dolgas CM, Herman JP (2002) Stress activation of cortex and hippocampus is modulated by sex and stage of estrus. Endocrinology 143(7):2534-2540

Frick KM, Berger-Sweeney J (2001) Spatial reference memory and neocortical neurochemistry vary with the estrous cycle in C57BL/6 mice. Behav Neurosci 115(1):229-237

Frick KM, Gresack JE (2003) Sex differences in the behavioral response to spatial and object novelty in adult C57BL/6 mice. Behav Neurosci 117(6):1283-1291. doi:10.1037/0735-7044.117.6.1283

Frick KM, Burlingame LA, Arters JA, Berger-Sweeney J (2000) Reference memory, anxiety and estrous cyclicity in C57BL/ 6NIA mice are affected by age and sex. Neuroscience 95(1): 293-307

Frye CA (1995) Estrus-associated decrements in a water maze task are limited to acquisition. Physiol Behav 57(1):5-14

Frye CA, Petralia SM, Rhodes ME (2000) Estrous cycle and sex differences in performance on anxiety tasks coincide with increases in hippocampal progesterone and 3alpha, 5alpha-THP. Pharmacol Biochem Behav 67(3):587-596

Frye CA, Duffy CK, Walf AA (2007) Estrogens and progestins enhance spatial learning of intact and ovariectomized rats in the object placement task. Neurobiol Learn Mem 88(2):208-216. doi:10.1016/j.nlm.2007.04.003

Gala RR, Westphal U (1965) Corticosteroid-binding globulin in the rat: possible role in the initiation of lactation. Endocrinology 76:1079-1088

Gass P, Reichardt HM, Strekalova T, Henn F, Tronche F (2001) Mice with targeted mutations of glucocorticoid and mineralocorticoid receptors: Models for depression and anxiety? Physiol Behav 73(5):811-825

Gouveia A Jr, dos Santos UD, Felisbino FE, de Afonseca TL, Antunes G, Morato S (2004) Influence of the estrous cycle on the behavior of rats in the elevated T-maze. Behav Process 67(2):167-171. doi:10.1016/j.beproc.2004.03.018

Groeneweg FL, Karst H, de Kloet ER, Joels M (2011) Rapid nongenomic effects of corticosteroids and their role in the central stress response. J Endocrinol 209(2):153-167. doi:10.1530/JOE-10-0472

Guo M, Wu CF, Liu W, Yang JY, Chen D (2004) Sex difference in psychological behavior changes induced by long-term social isolation in mice. Prog Neuropsychopharmacol Biol Psychiatry 28(1):115-121. doi:10.1016/j.pnpbp.2003.09.027

Herzog CJ, Czeh B, Corbach S, Wuttke W, Schulte-Herbruggen O, Hellweg R, Flugge G, Fuchs E (2009) Chronic social instability stress in female rats: a potential animal model for female depression.
Neuroscience 159(3):982-992. doi:10.1016/j.neuroscience.2009. 01.059

Hodes GE, Shors TJ (2005) Distinctive stress effects on learning during puberty. Horm Behav 48(2):163-171. doi:10.1016/j.yhbeh. 2005.02.008

Hodes GE, Shors TJ (2007) Learning during middle age: A resistance to stress? Neurobiol Aging 28(11):1783-1788. doi:10.1016/j. neurobiolaging.2006.07.012

Johnston AL, File SE (1991) Sex differences in animal tests of anxiety. Physiol Behav 49(2):245-250

Karandrea D, Kittas C, Kitraki E (2000) Contribution of sex and cellular context in the regulation of brain corticosteroid receptors following restraint stress. Neuroendocrinology 71(6):343-353

Karst H, Berger S, Turiault M, Tronche F, Schutz G, Joels M (2005) Mineralocorticoid receptors are indispensable for nongenomic modulation of hippocampal glutamate transmission by corticosterone. Proc Natl Acad Sci USA 102(52):19204-19207. doi: 10.1073/pnas.0507572102

Karst H, Berger S, Erdmann G, Schutz G, Joels M (2010) Metaplasticity of amygdalar responses to the stress hormone corticosterone. Proc Natl Acad Sci USA 107(32):14449-14454. doi:10.1073/pnas.0914381107

Kennett GA, Chaouloff F, Marcou M, Curzon G (1986) Female rats are more vulnerable than males in an animal model of depression: the possible role of serotonin. Brain Res 382(2):416-421

Kessler RC (2003) Epidemiology of women and depression. J Affect Disord 74(1):5-13

Kessler RC, Sonnega A, Bromet E, Hughes M, Nelson CB (1995) Posttraumatic stress disorder in the National Comorbidity Survey. Arch Gen Psychiatry 52(12):1048-1060

Kitay JI (1961) Sex differences in adrenal cortical secretion in the rat. Endocrinology 68:818-824

Kitraki E, Kremmyda O, Youlatos D, Alexis M, Kittas C (2004) Spatial performance and corticosteroid receptor status in the 21day restraint stress paradigm. Ann N Y Acad Sci 1018:323-327. doi:10.1196/annals.1296.039.1018/1/323[pii]

Korol DL, Malin EL, Borden KA, Busby RA, Couper-Leo J (2004) Shifts in preferred learning strategy across the estrous cycle in female rats. Horm Behav 45(5):330-338. doi:10.1016/j.yhbeh. 2004.01.005

Lamberty Y, Gower AJ (1988) Investigation into sex-related differences in locomotor activity, place learning and passive avoidance responding in NMRI mice. Physiol Behav 44(6): 787-790

Le Mevel JC, Abitbol S, Beraud G, Maniey J (1979) Temporal changes in plasma adrenocorticotropin concentration after repeated neurotropic stress in male and female rats. Endocrinology 105(3):812-817

Leret ML, Molina-Holgado F, Gonzalez MI (1994) The effect of perinatal exposure to estrogens on the sexually dimorphic response to novelty. Physiol Behav 55(2):371-373

Leuner B, Shors TJ (2006) Learning during motherhood: a resistance to stress. Horm Behav 50(1):38-51. doi:10.1016/j.yhbeh. 2006.01.002

Lewinsohn PM, Rohde P, Seeley JR (1998) Major depressive disorder in older adolescents: prevalence, risk factors, and clinical implications. Clin Psychol Rev 18(7):765-794

Li S, Wang C, Wang W, Dong H, Hou P, Tang Y (2008) Chronic mild stress impairs cognition in mice: from brain homeostasis to behavior. Life Sci 82(17-18):934-942. doi:10.1016/j.lfs.2008. 02.010

Lin EJ, Choi E, Liu X, Martin A, During MJ (2011) Environmental enrichment exerts sex-specific effects on emotionality in C57BL/ $6 \mathrm{~J}$ mice. Behav Brain Res 216(1):349-357. doi:10.1016/j.bbr. 2010.08.019 
Luine V, Villegas M, Martinez C, McEwen BS (1994) Repeated stress causes reversible impairments of spatial memory performance. Brain Res 639(1):167-170

Luine VN, Beck KD, Bowman RE, Frankfurt M, Maclusky NJ (2007) Chronic stress and neural function: accounting for sex and age. J Neuroendocrinol 19(10):743-751. doi:10.1111/j.1365-2826. 2007.01594.x

Lupien SJ, McEwen BS (1997) The acute effects of corticosteroids on cognition: integration of animal and human model studies. Brain Res Brain Res Rev 24(1):1-27

Maguire GA (2002) Comprehensive understanding of schizophrenia and its treatment. Am J Health Syst Pharm 59(17 Suppl 5): S4-S11

Marcondes FK, Miguel KJ, Melo LL, Spadari-Bratfisch RC (2001) Estrous cycle influences the response of female rats in the elevated plus-maze test. Physiol Behav 74(4-5):435-440

Markowska AL (1999) Sex dimorphisms in the rate of age-related decline in spatial memory: relevance to alterations in the estrous cycle. J Neurosci 19(18):8122-8133

McEwen BS (2010) Stress, sex, and neural adaptation to a changing environment: mechanisms of neuronal remodeling. Ann N Y Acad Sci 1204(Suppl):E38-E59. doi:10.1111/j.1749-6632.2010. 05568.x

McEwen BS, De Kloet ER, Rostene W (1986) Adrenal steroid receptors and actions in the nervous system. Physiol Rev 66(4):1121-1188

McGrath JJ (2006) Variations in the incidence of schizophrenia: data versus dogma. Schizophr Bull 32(1):195-197. doi:10.1093/ schbul/sbi052

McLaughlin KJ, Gomez JL, Baran SE, Conrad CD (2007) The effects of chronic stress on hippocampal morphology and function: an evaluation of chronic restraint paradigms. Brain Res 1161: 56-64. doi:10.1016/j.brainres.2007.05.042

Mora S, Dussaubat N, Diaz-Veliz G (1996) Effects of the estrous cycle and ovarian hormones on behavioral indices of anxiety in female rats. Psychoneuroendocrinology 21(7):609-620

Nagi S, Virgo BB (1982) The effects of spironolactone on reproductive functions in female rats and mice. Toxicol Appl Pharmacol 66(2):221-228

Nolen-Hoeksema S (2001) Gender differences in depression. Curr Dir Psychol Sci 10(5):173-176

Oitzl MS, de Kloet ER (1992) Selective corticosteroid antagonists modulate specific aspects of spatial orientation learning. Behav Neurosci 106(1):62-71

Oitzl MS, Champagne DL, van der Veen R, de Kloet ER (2010) Brain development under stress: hypotheses of glucocorticoid actions revisited. Neurosci Biobehav Rev 34(6):853-866. doi: 10.1016/j.neubiorev.2009.07.006

O'Leary TP, Savoie V, Brown RE (2011) Learning, memory and search strategies of inbred mouse strains with different visual abilities in the Barnes maze. Behav Brain Res 216(2):531-542. doi:10.1016/j.bbr.2010.08.030

Oomen CA, Soeters H, Audureau N, Vermunt L, van Hasselt FN, Manders EM, Joels M, Lucassen PJ, Krugers H (2010) Severe early life stress hampers spatial learning and neurogenesis, but improves hippocampal synaptic plasticity and emotional learning under high-stress conditions in adulthood. J Neurosci 30(19):6635-6645. doi:10.1523/JNEUROSCI.0247-10.2010

Oomen CA, Soeters H, Audureau N, Vermunt L, van Hasselt FN, Manders EM, Joels M, Krugers H, Lucassen PJ (2011) Early maternal deprivation affects dentate gyrus structure and emotional learning in adult female rats. Psychopharmacology 214(1):249-260. doi:10.1007/s00213-010-1922-8

Packard MG, Knowlton BJ (2002) Learning and memory functions of the basal ganglia. Annu Rev Neurosci 25:563-593. doi: 10.1146/annurev.neuro.25.112701.142937
Palanza P (2001) Animal models of anxiety and depression: How are females different? Neurosci Biobehav Rev 25(3):219-233

Palanza P, Gioiosa L, Parmigiani S (2001) Social stress in mice: gender differences and effects of estrous cycle and social dominance. Physiol Behav 73(3):411-420

Paris JJ, Frye CA (2008) Estrous cycle, pregnancy, and parity enhance performance of rats in object recognition or object placement tasks. Reproduction 136(1):105-115. doi:10.1530/ REP-07-0512

Perrot-Sinal TS, Kostenuik MA, Ossenkopp KP, Kavaliers M (1996) Sex differences in performance in the Morris water maze and the effects of initial nonstationary hidden platform training. Behav Neurosci 110(6):1309-1320

Pleil KE, Williams CL (2010) The development and stability of estrogen-modulated spatial navigation strategies in female rats. Horm Behav 57(3):360-367. doi:10.1016/j.yhbeh.2010.01.005

Pollard I, White BM, Bassett JR, Cairncross KD (1975) Plasma glucocorticoid elevation and desynchronization of the estrous cycle following unpredictable stress in the rat. Behav Biol 14(01):103-108

Pompili A, Tomaz C, Arnone B, Tavares MC, Gasbarri A (2010) Working and reference memory across the estrous cycle of rat: a long-term study in gonadally intact females. Behav Brain Res 213(1):10-18. doi:10.1016/j.bbr.2010.04.018

Qian X, Droste SK, Gutierrez-Mecinas M, Collins A, Kersante F, Reul JM, Linthorst AC (2011) A rapid release of corticosteroidbinding globulin from the liver restrains the glucocorticoid hormone response to acute stress. Endocrinology 152(10):3738 3748. doi:10.1210/en.2011-1008

Reul JM, de Kloet ER (1985) Two receptor systems for corticosterone in rat brain: microdistribution and differential occupation. Endocrinology 117(6):2505-2511

Rodgers RJ, Cole JC (1993) Influence of social isolation, gender, strain, and prior novelty on plus-maze behaviour in mice. Physiol Behav 54(4):729-736

Roof RL (1993) Neonatal exogenous testosterone modifies sex difference in radial arm and Morris water maze performance in prepubescent and adult rats. Behav Brain Res 53(1-2):1-10

Rozeboom AM, Akil H, Seasholtz AF (2007) Mineralocorticoid receptor overexpression in forebrain decreases anxiety-like behavior and alters the stress response in mice. Proc Natl Acad Sci USA 104(11):4688-4693. doi:10.1073/pnas.0606067104

Schmidt MV, Scharf SH, Liebl C, Harbich D, Mayer B, Holsboer F, Muller MB (2010) A novel chronic social stress paradigm in female mice. Horm Behav 57(4-5):415-420. doi:10.1016/j.yhbeh.2010. 01.010

Schwabe L, Dalm S, Schachinger H, Oitzl MS (2008) Chronic stress modulates the use of spatial and stimulus-response learning strategies in mice and man. Neurobiol Learn Mem 90(3):495503. doi: $10.1016 /$ j.nlm.2008.07.015

Schwabe L, Schachinger H, de Kloet ER, Oitzl MS (2010) Corticosteroids operate as a switch between memory systems. J Cognitive Neurosci 22(7):1362-1372. doi:10.1162/jocn. 2009.21278

Seale JV, Wood SA, Atkinson HC, Bate E, Lightman SL, Ingram CD, Jessop DS, Harbuz MS (2004) Gonadectomy reverses the sexually diergic patterns of circadian and stress-induced hypothalamic-pituitary-adrenal axis activity in male and female rats. J Neuroendocrinol 16(6):516-524. doi:10.1111/j.1365-2826. 2004.01195.x

Soldin OP, Mattison DR (2009) Sex differences in pharmacokinetics and pharmacodynamics. Clin Pharmacokinet 48(3):143-157. doi:10.2165/00003088-200948030-00001

Steiner M, Dunn E, Born L (2003) Hormones and mood: from menarche to menopause and beyond. J Affect Disord 74(1): $67-83$ 
Sutcliffe JS, Marshall KM, Neill JC (2007) Influence of gender on working and spatial memory in the novel object recognition task in the rat. Behav Brain Res 177(1):117-125. doi:10.1016/j.bbr. 2006.10.029

Tannenbaum B, Rowe W, Sharma S, Diorio J, Steverman A, Walker M, Meaney MJ (1997) Dynamic variations in plasma corticosteroid-binding globulin and basal HPA activity following acute stress in adult rats. J Neuroendocrinol 9(3):163-168

Tropp J, Markus EJ (2001) Sex differences in the dynamics of cue utilization and exploratory behavior. Behav Brain Res 119(2): 143-154

Turner BB (1992) Sex differences in the binding of type I and type II corticosteroid receptors in rat hippocampus. Brain Res 581(2): 229-236

Turner BB (1997) Influence of gonadal steroids on brain corticosteroid receptors: a minireview. Neurochem Res 22(11):1375-1385

Turner BB, Weaver DA (1985) Sexual dimorphism of glucocorticoid binding in rat brain. Brain Res 343(1):16-23

Viau V, Meaney MJ (1991) Variations in the hypothalamic-pituitaryadrenal response to stress during the estrous cycle in the rat. Endocrinology 129(5):2503-2511

Voikar V, Koks S, Vasar E, Rauvala H (2001) Strain and gender differences in the behavior of mouse lines commonly used in transgenic studies. Physiol Behav 72(1-2):271-281

Waddell J, Bangasser DA, Shors TJ (2008) The basolateral nucleus of the amygdala is necessary to induce the opposing effects of stressful experience on learning in males and females. J Neurosci 28(20):5290-5294. doi:10.1523/JNEUROSCI.1129-08.2008

Walf AA, Frye CA (2007) Estradiol decreases anxiety behavior and enhances inhibitory avoidance and gestational stress produces opposite effects. Stress 10(3):251-260. doi:10.1080/ 00958970701220416

Walf AA, Rhodes ME, Frye CA (2006) Ovarian steroids enhance object recognition in naturally cycling and ovariectomized, hormone-primed rats. Neurobiol Learn Mem 86(1):35-46. doi: 10.1016/j.nlm.2006.01.004

Walf AA, Koonce C, Manley K, Frye CA (2009) Proestrous compared to diestrous wildtype, but not estrogen receptor beta knockout, mice have better performance in the spontaneous alternation and object recognition tasks and reduced anxiety-like behavior in the elevated plus and mirror maze. Behav Brain Res 196(2):254-260. doi:10.1016/j.bbr.2008.09.016
Warren SG, Juraska JM (1997) Spatial and nonspatial learning across the rat estrous cycle. Behav Neurosci 111(2):259-266

Weiss IC, Pryce CR, Jongen-Relo AL, Nanz-Bahr NI, Feldon J (2004) Effect of social isolation on stress-related behavioural and neuroendocrine state in the rat. Behav Brain Res 152(2):279 295. doi:10.1016/j.bbr.2003.10.015

White NM, McDonald RJ (2002) Multiple parallel memory systems in the brain of the rat. Neurobiol Learn Mem 77(2):125-184. doi: 10.1006/nlme.2001.4008

Williams TD, Carter DA, Lightman SL (1985) Sexual dimorphism in the posterior pituitary response to stress in the rat. Endocrinology 116(2):738-740

Wittchen HU, Jacobi F (2005) Size and burden of mental disorders in Europe-a critical review and appraisal of 27 studies. Eur Neuropsychopharmacol 15(4):357-376. doi:10.1016/j.euron euro.2005.04.012

Wood GE, Shors TJ (1998) Stress facilitates classical conditioning in males, but impairs classical conditioning in females through activational effects of ovarian hormones. Proc Natl Acad Sci USA 95(7):4066-4071

Wood GE, Beylin AV, Shors TJ (2001) The contribution of adrenal and reproductive hormones to the opposing effects of stress on trace conditioning in males versus females. Behav Neurosci 115(1):175-187

Woolley CS, McEwen BS (1992) Estradiol mediates fluctuation in hippocampal synapse density during the estrous cycle in the adult rat. J Neurosci 12(7):2549-2554

Woolley CS, Gould E, Frankfurt M, McEwen BS (1990a) Naturally occurring fluctuation in dendritic spine density on adult hippocampal pyramidal neurons. J Neurosci 10(12):4035-4039

Woolley CS, Gould E, McEwen BS (1990b) Exposure to excess glucocorticoids alters dendritic morphology of adult hippocampal pyramidal neurons. Brain Res 531(1-2):225-231

Wotjak CT (2004) Of mice and men: potentials and caveats of behavioural experiments with mice. BIF Futura 19:158-169

Young EA, Altemus M (2004) Puberty, ovarian steroids, and stress. Ann N Y Acad Sci 1021:124-133. doi:10.1196/annals.1308.013

Zimmerberg B, Farley MJ (1993) Sex differences in anxiety behavior in rats: role of gonadal hormones. Physiol Behav 54(6): $1119-1124$ 